Th1s report was prepared as an account of Government sponsored work. Neither the Untted Ttates, nor the Commission, nor any person acting on behalf of the Com. Nether

A, nor the Commission, nor any person acting on behalf of the commission:

A. Makes any warranty or representation, expressed or Implied, with respect to the accu-* racy, completeness; or -usefulness of the information contained in this report, or that the use
of any information, apparatus, method, or process disclosed in this report may not infringe privately owned rights; or

B. Assumes any liabsilties with respect to the use of, or for damages resulting from the of any information, apparatus, method, or process disclosed in this report.

As used in the above, "person acting on behalf of the Commleston" Includes any employee or contractor of the Commission, or employee of such contractor, to the extent that such employee or contractor of the Commission, of employee of such contractor prepares, disseminates, or provides access to, any informatiop pursuant to bls employment or contract with the Commission, or his employment with such contractor.

ARGONNE NATIONAL LABORATORY

9700 South Cass Avenue

Argonne, Illinois 60439

H.C. $\$ 2.00, \operatorname{MNN}, 50$

\title{
PHYSICS DIVISION SUMMARY REPORT
}

May 1966

Lowell M. Bollinger, Division Director

Preceding Summary Reports:

ANL-7108, April-December 1965

ANL-7179, January-February 1966

ANL-7198, March-April 1966

RELEASED FOR ANNOUNCEMENT

IN NUCLEAR SCIENCE ABSTRACTS

Operated by The University of Chicago

under

Contract W-31-109-eng-38

with the

U. S. Atomic Energy Commission 


\section{DISCLAIMER}

This report was prepared as an account of work sponsored by an agency of the United States Government. Neither the United States Government nor any agency Thereof, nor any of their employees, makes any warranty, express or implied, or assumes any legal liability or responsibility for the accuracy, completeness, or usefulness of any information, apparatus, product, or process disclosed, or represents that its use would not infringe privately owned rights. Reference herein to any specific commercial product, process, or service by trade name, trademark, manufacturer, or otherwise does not necessarily constitute or imply its endorsement, recommendation, or favoring by the United States Government or any agency thereof. The views and opinions of authors expressed herein do not necessarily state or reflect those of the United States Government or any agency thereof. 


\section{DISCLAIMER}

Portions of this document may be illegible in electronic image products. Images are produced from the best available original document. 
FOREWORD

The Physics Summary is issued several times per year for the information of the members of the Division and a limited number of other persons interested in the progress of the work. It includes short reports on highlights of the current research, abstracts or short summaries of oral presentations at meetings, abstracts of papers recently accepted for publication, and publication notices of papers appearing:in recent journals and books. Many of these reports cover work still in progress; the results and data they present are therefore preliminary, tentative, and often incomplete.

The research presented in any one is sue of the Summary is only a small random sample of the work of the Physics Division. For a comprehensive overview, the reader is referred to the ANL Physics Division. Annual Review issued each summer, the most recent being Argonne National Laboratory Report ANL-7081 which reports research in the year ending $31 \mathrm{March} 1965$.

The issuance of these reports is not intended to constitute publication in any sense of the word. Final results will be submitted for publication in regular professional journals or, in special cases, presented in ANL Topical Reports. 
I. RESEARCH HIGHLIGHTS

Discrepancies in Proton-Transfer Reactions to States 1 with Different Isobaric Spin

R. H. Siemssen, G. C. Morrison, B. Zeidman, and H. Fuchs

II. ABSTRACTS AND PAPERS PRESENTED AT MEETINGS

Seminar on Uses of Computers in. Analysis of

Experimental Data and Control of Nuclear Facilities Argonne National Laboratory, Argonne, Illinois, 4-6 May 1966

Fourteenth Annual Conference on Mass Spectrometry and Allied Topics

Dallas, Texas, 22-27 May 1966

III. ABSTRACTS OF PAPERS ACCEPTED FOR PUBLICATION

IV. PUBLICATIONS SINCE THE LAST REPORT

Papers

Abstracts and Papers Presented at Meetings

Informal Report 


\section{RESEARCH HIGHLIGHTS}

These research highlights are Physics Division contributions to the Physical Research Monthly Report which the Laboratory Director's Office sends to the Division of Research of the U.S. Atomic Energy Commission. They report interesting work that is currently in progress or that has just been completed.

\section{DISCREPANCIES IN PROTON-TRANSFER REACTIONS TO STATES WITH DIFFERENT ISOBARIC SPIN}

R. H. Siemssen, G. C. Morrison, B. Zeidman, and H. Fuchs*

It is widely accepted that the direct reactions $(d, n)$ and $\left(\mathrm{He}^{3}, \mathrm{~d}\right)$ are analogous processes involving proton transfer and that they should therefore yield the same reduced widths (spectroscopic factors). We have compared the relative spectroscopic factors from $\left(\mathrm{He}^{3}, \mathrm{~d}\right)$ reactions with those from $(d, n)$ reactions for the low $T=0$ and $T=1$ states in the odd-odd nuclei $\mathrm{B}^{10}, \mathrm{~N}^{14}$, and $\mathrm{Al}^{26}$. In contrast to expectation, we find that in each case a smaller value of the relative spectroscopic factor for the states with isobaric spin $T=1$ is deduced from the $(d, n)$ reaction than from the $\left(\mathrm{He}^{3}\right.$, d) reaction, the spectroscopic factors being normalized to the $T=0$ ground states for the two reactions.

The $\left(\mathrm{He}^{3}\right.$, d) reactions leading to $\mathrm{B}^{10}$ and $\mathrm{Al}^{26}$ at $E\left(\mathrm{He}^{3}\right)=17 \mathrm{MeV}$ and to $\mathrm{N}^{14}$ at 13 and $17 \mathrm{MeV}$ were studied at the Argonne tandem Van de Graaff with a counter telescope. The $(d, n)$ reactions leading to $\mathrm{N}^{14}$ and $\mathrm{Al}^{26}$ were measured at $\mathrm{E}(\mathrm{d})=5.5 \mathrm{MeV}$ at the Hahn Meitner Institut with a pulsed-beam time-of-flight spectrometer. Both

\footnotetext{
*Hahn Meitner Institut, Berlin, Germany.
} 
sets of observations were at forward angles. Relative spectroscopic factors were obtained from the reactions studied, as well as from other data, by means of DWBA theory with reasonable distortion parameters. Since the lowest $\mathrm{T}=1$ state in an odd-odd light nucleus is bracketed by $\mathrm{T}=0$ states with little difference in excitation energy, the relative spectroscopic factors are rather insensitive to the choice of the distortion parameters. Furthermore, all final states within one nucleus for which the spectroscopic factors are compared are formed by proton capture with the same orbital-angular-momentum transfer $\left(\ell=1\right.$ for $B^{10}$ and $\mathrm{N}^{14}, \ell=2$ for $\mathrm{Al}^{26}$ ). It can be seen from Table $\mathrm{I}$ that the relative spectroscopic factors for the $\mathrm{T}=0$ states are approximately the same for the $\left(\mathrm{He}^{3}, \mathrm{~d}\right)$ and the $(\mathrm{d}, \mathrm{n})$ data, whereas for the $\mathrm{T}=1$ transitions the values from the $(\mathrm{d}, \mathrm{n})$ reaction are less than those from the $\left(\mathrm{He}^{3}, \mathrm{~d}\right)$ reaction. This effect exists at all the energies studied, although the magnitude of the effect may exhibit a slight energy dependence.

The difference between the relative yields of the transitions to the $\mathrm{T}=1$ states in the $(d, \mathrm{n})$ and the $\left(\mathrm{He}^{3}, \mathrm{~d}\right)$ reactions is not understood. Originally it was thought that exchange or cluster effects present in the $(d, n)$ reaction might be responsible for the observed difference. If exchange stripping in the $(d, n)$ reaction involves only the low-lying $T=0$ states of the core as intermediate parent states, then this mechanism is not expected to contribute to the $T=1$ final state. If exchange effects are that important in the $(d, n)$ reaction, however, we would also expect that the relative spectroscopic factors from the $(d, n)$ and the $\left(\mathrm{He}^{3}, d\right)$ reaction to the various $\mathrm{T}=0$ states should differ markedly since the spectroscopic amplitudes from the direct and the exchange terms are unrelated. This is in contradiction to observation.

Another explanation of the observed differences in spectroscopic factors is that the distorting potentials of the exit channel may depend on the configuration of the final state. Similarly, the form of the 
TABLE I. Relative spectroscopic factors of $\mathrm{B}^{10}, \mathrm{~N}^{14}$, and $\mathrm{Al}^{26}$ from the $\mathrm{Be}^{9}(\mathrm{~d}, \mathrm{n}) \mathrm{B}^{10}$, $\mathrm{Be}^{9}\left(\mathrm{He}^{3}, \mathrm{~d}\right) \mathrm{B}^{10}, \mathrm{C}^{13}(\mathrm{~d}, \mathrm{n}) \mathrm{N}^{14}, \mathrm{C}^{13}\left(\mathrm{He}^{3}, \mathrm{~d}\right) \mathrm{N}^{14}, \mathrm{Mg}^{25}(\mathrm{~d}, \mathrm{n}) \mathrm{Al}^{26}$, and $\mathrm{Mg}^{25}\left(\mathrm{He}^{3}\right.$, d)Al26 reactions.

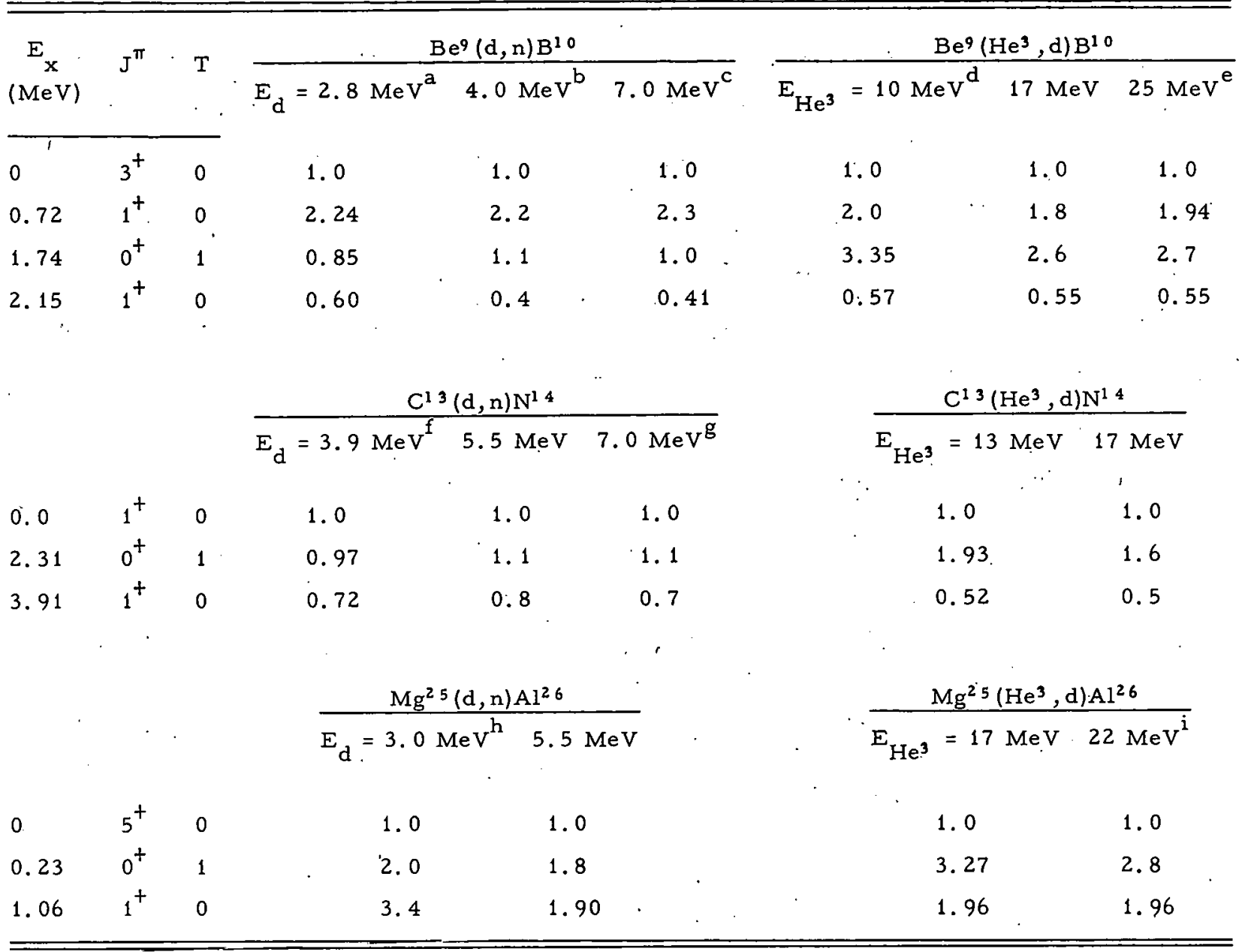

${ }^{a}$. H. Siemssen, M. Cosack, and R. Felst, Nucl. Phys. 69, 209 (1965).

${ }^{b}$ G. C. Morrison, A. T. G. Ferguson, and J. E. Evans, in Proceedings of the Rutherford Jubilee International Conference, Manchester, 1961, edited by J. B. Birks (Heywood and Co., London, 1961), p. 575.

${ }^{c}$ S. G. Buccino and A. B. Smith, Phys. Letters 19, 234 (1965).

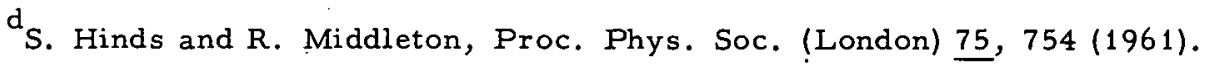

$e_{H .}$ E. Wegner and W. S. Hall, Phys. Rev. 119, 1654 (1960).

${ }^{\text {f }}$. E. Benenson and B. Yaramis, Phys. Rev. 129, 720 (1963).

g. A. Cookson and D. Dandy (private communication).

$h_{R}$. B. Weinberg and R. B. Taylor (private communication).

i A. G. Blair (private communication). 
radial wave function of the captured proton may depend on whether it is captured into a $\mathrm{T}=0$ or a $\mathrm{T}=1$ state. Because of the strong absorption of the $\mathrm{He}^{3}$ particle, the $\left(\mathrm{He}^{3}, \mathrm{~d}\right)$.reaction is expected to be more localized on the nuclear surface than the $(d, n)$ reaction is; changes in the tail of the bound-state wave function will therefore have a greater effect on the $\left(\mathrm{He}^{3}\right.$, d) reaction. Although there may be some theoretical justification for expecting the wave function for the $T=1$ state to be different from that of the corresponding $\mathrm{T}=0$ state, a large difference would be required to reproduce the observed discrepancies between the $(d, n)$ and the $\left(\mathrm{He}^{3}, \mathrm{~d}\right)$ reactions. The observed discrepancy between $(d, n)$ and $\left(\mathrm{He}^{3}, \mathrm{~d}\right)$ spectroscopic factors is rather serious because it shows that for light nuclei even the relative spectroscopic factors extracted from direct-reaction theories must be taken with caution until a detailed explanation of the observed effects can be given. 


\section{ABSTRACTS AND PAPERS PRESENTED AT MEETINGS}

The abstracts and summaries that follow are not necessarily identical to those submitted for the meeting. In some cases, the authors have corrected or expanded abstracts; and summaries of contributed papers commonly have been shortened.

Seminar on Uses of Computers in Analysis of Experimental Data and Control of Nuclear Facilities Argonne National Laboratory, Argonne, Illinois, 4-6 May 1966

AN ON-LINE COMPUTER SYSTEM IN USE WITH LOW-ENERGY NUCLEAR PHYSICS EXPERIMENTS

D. S. Gemmell

A computer system (Figs. 1, 2) has been developed for on-line use with experiments performed at the 4-MeV Van de Graaff and. the Tandem Van de Graaff at Argonne National Laboratory. At the heart of the system are two small computers (ASI-2100 and ASI-210) which are linked together and to the CDC-3600 computer in the Applied Mathematics Division. The ASI-210 is used almost exclusively on-line at the Tandem. The ASI -2100 is used on-line about $25 \%$ of the time at the $4-\mathrm{MeV}$ Van de Graaff, and for the remainder of the time it is used for off-line data analysis and for small Fortran computations. Requests for use of the ASI -2100 by users at the various locations are supervised by a monitor program resident in the computer. The data link to the CDC-3600 computer gives the on-line experimenter rapid access to a very much higher level of computing power. Some of the hardware is pictured in Figs. $3-6$. 


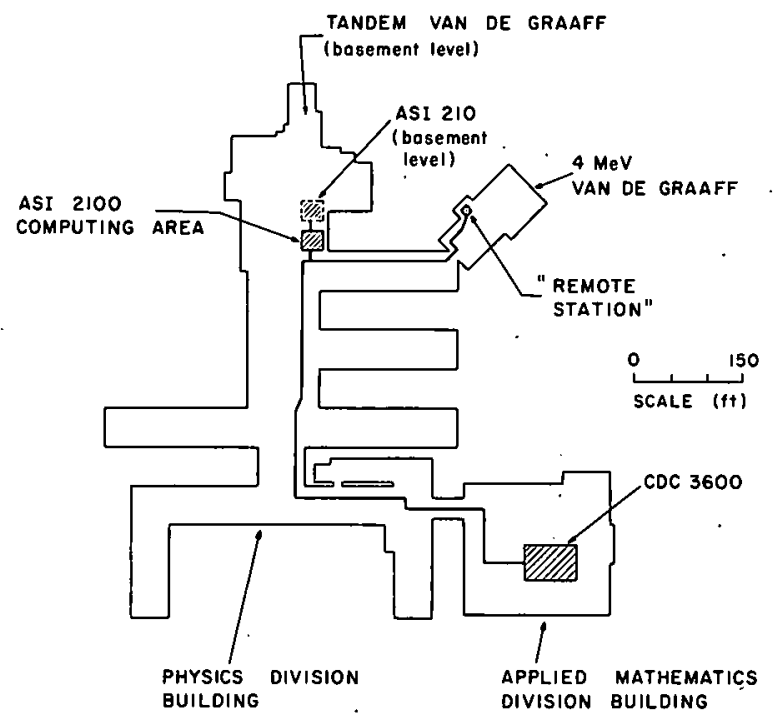

Fig. 1. Building plan showing the placement of the computers and the interconnecting links. The two small computers in the PHYLIS system are linked together through an interface (A70) and one of them (the ASI-2100) is also linked to the CDC-3600 in the Applied Mathematics Division. The ASI-210 is in one of the data-collection areas at the Tandem. The ASI-2100 is in a room situated between the Tandem and the 4-MeV Van de Graaff. A remote station for the ASI-2100 is set up in the data area of the latter accelerator.

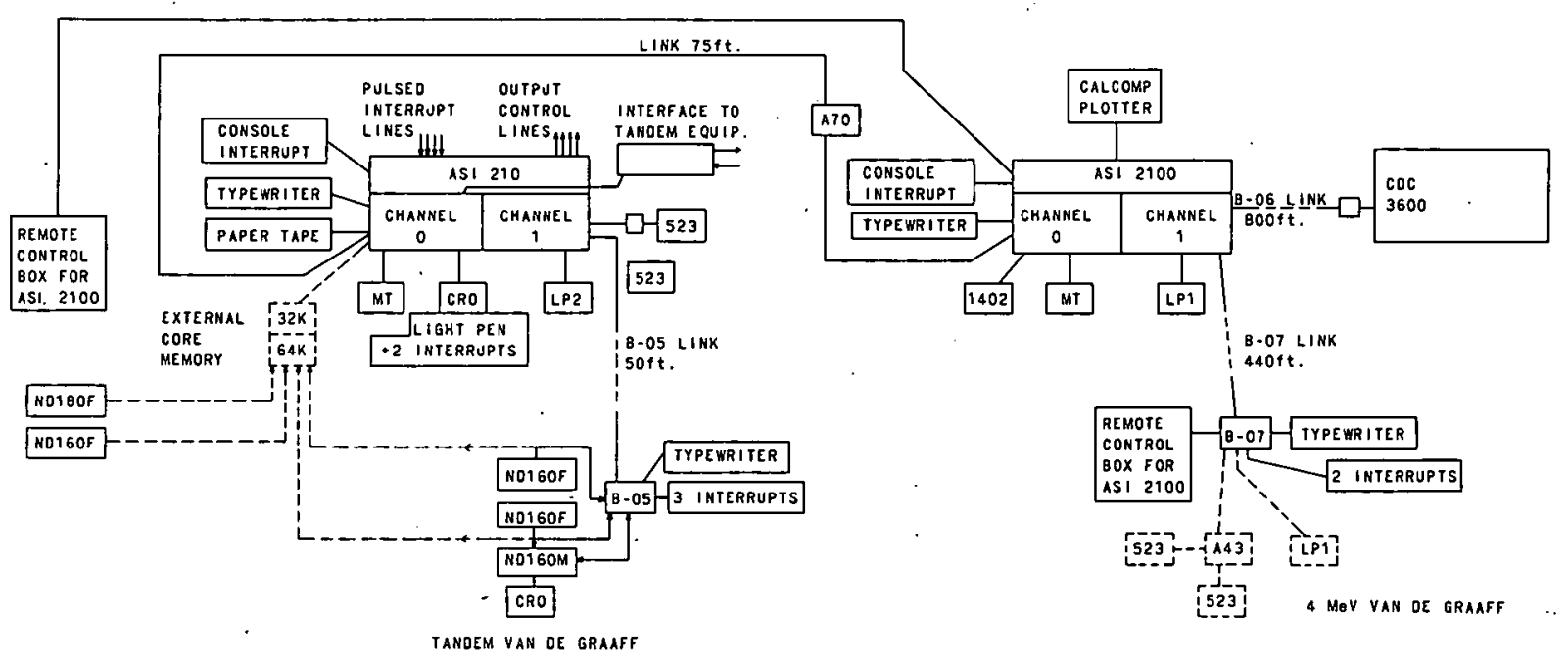

Fig. 2. Block diagram of the computing system. A great variety of external devices are attached to each of the small computers. Each is capable of running Fortran calculations. The ASI-210 is also interfaced to experimental equipment located at the Tandem (e.g., an ND-160 pulse-height analyzer, additional ADC units, NMR equipment measuring the magnetic field of the beam analyzer, scaler racks, etc.). 


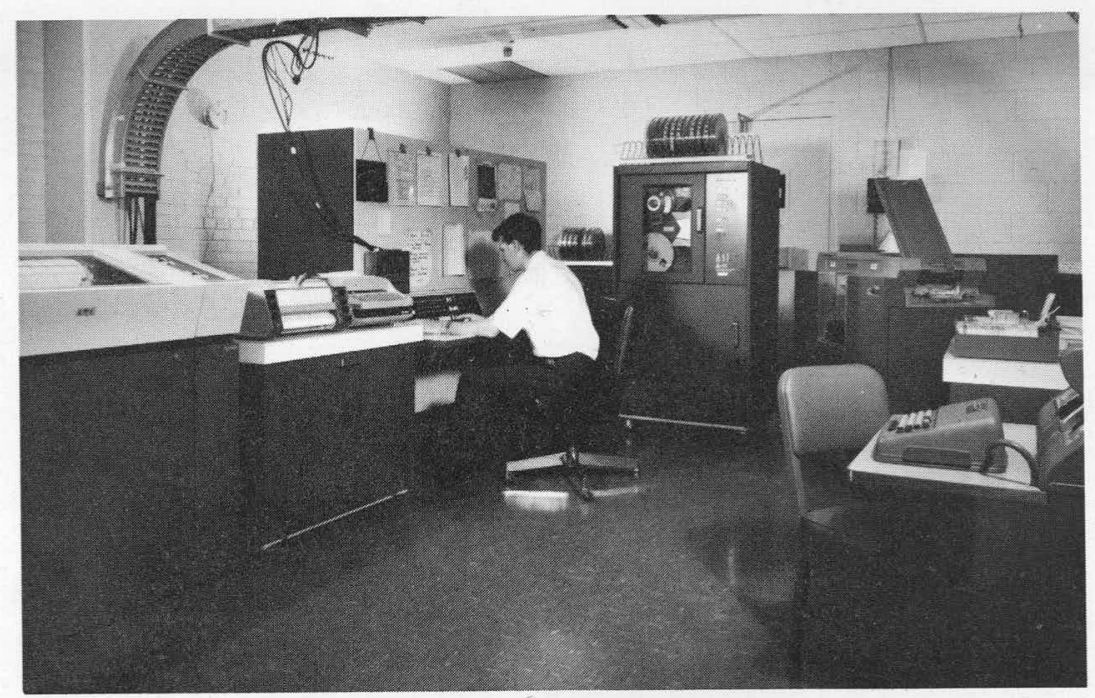

Fig. 3. View of the ASI-2100 computer and some peripheral equipment. From the left, the devices shown are an A64 line-printer, an A91 B plotter, an A32 typewriter, the ASI-2100 central processor, an A11 magnetic tape unit, an IBM-1402 card reader/punch, and an IBM-526 key-punch.

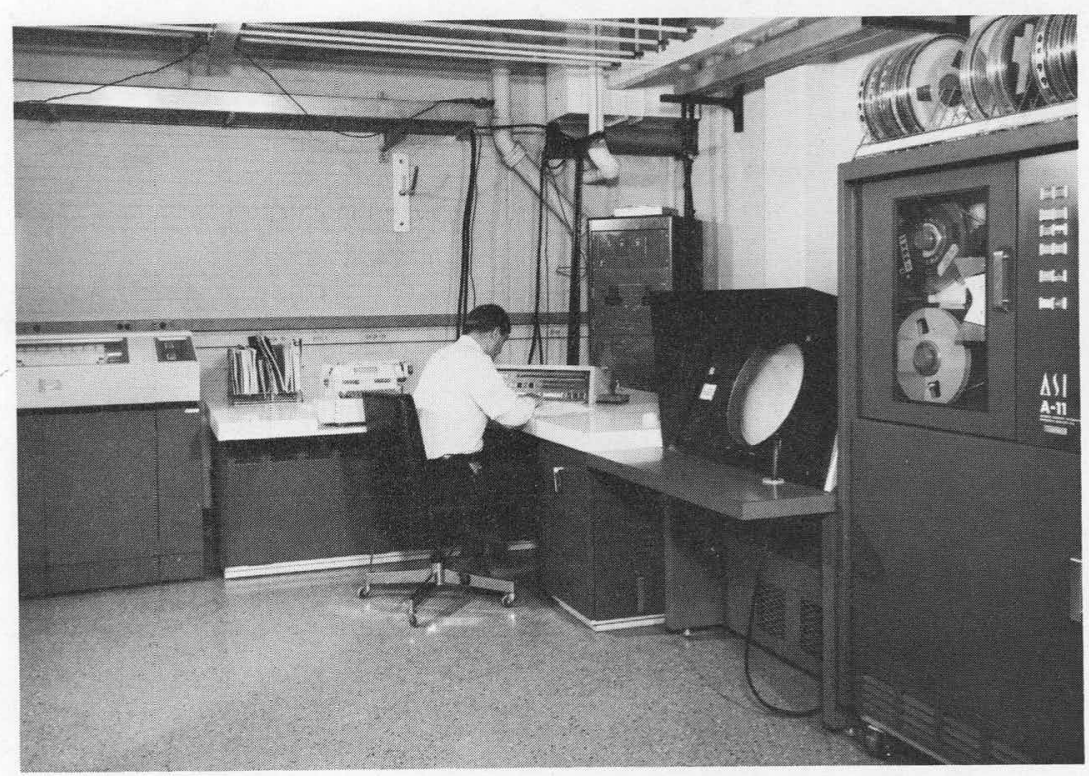

Fig. 4. View of the ASI-210 computer and some peripheral equipment located in the data collection area of the Tandem Van de Graaff. From the left, the devices shown are an A64 line-printer, the ASI-210 central processor, the interface to equipment at the Tandem (such as the beam controls, NMR readout, etc.), the DD16B oscilloscope, and an A11 magnetic tape unit. 


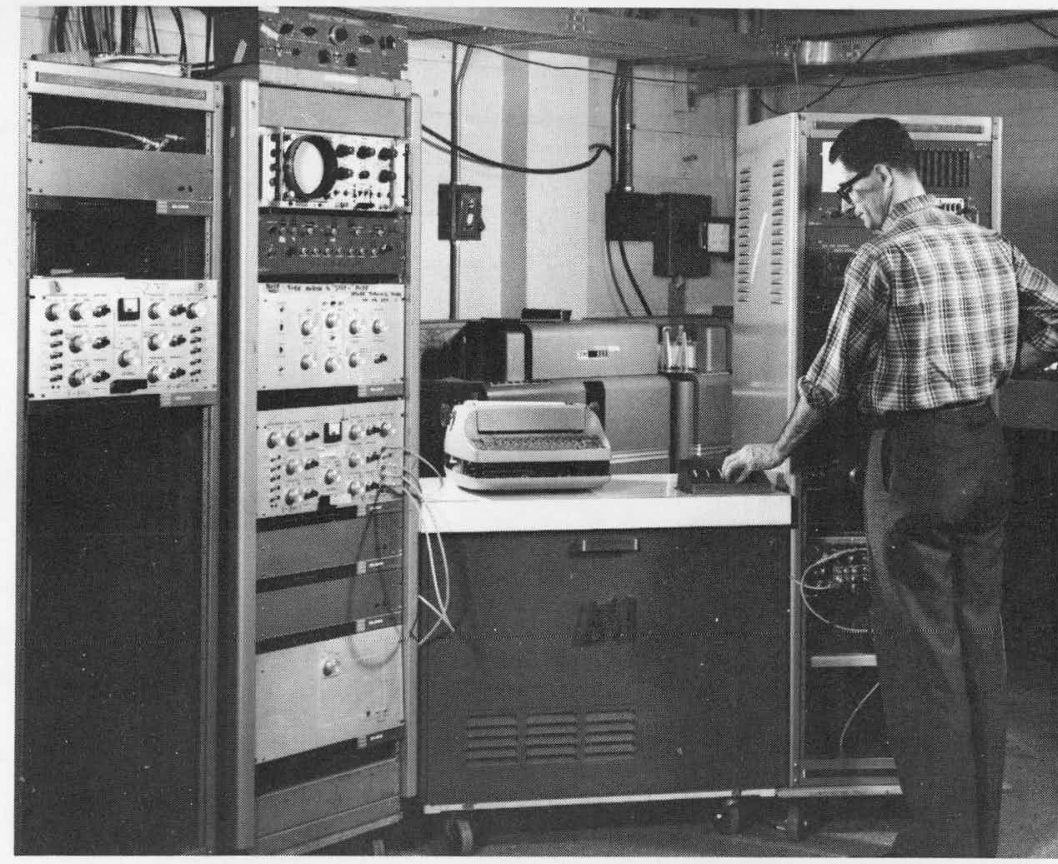

Fig. 5. The ND-160 pulse-height analyzer and the B-05 interface unit. The three manual interrupt buttons and an A32 typewriter can be seen. The rack behind the operator contains electronics which control the mode of the analyzer memory unit (ND 160M) and controls for other experimental equipment (e.g., positioning controls for movable detectors, etc.).

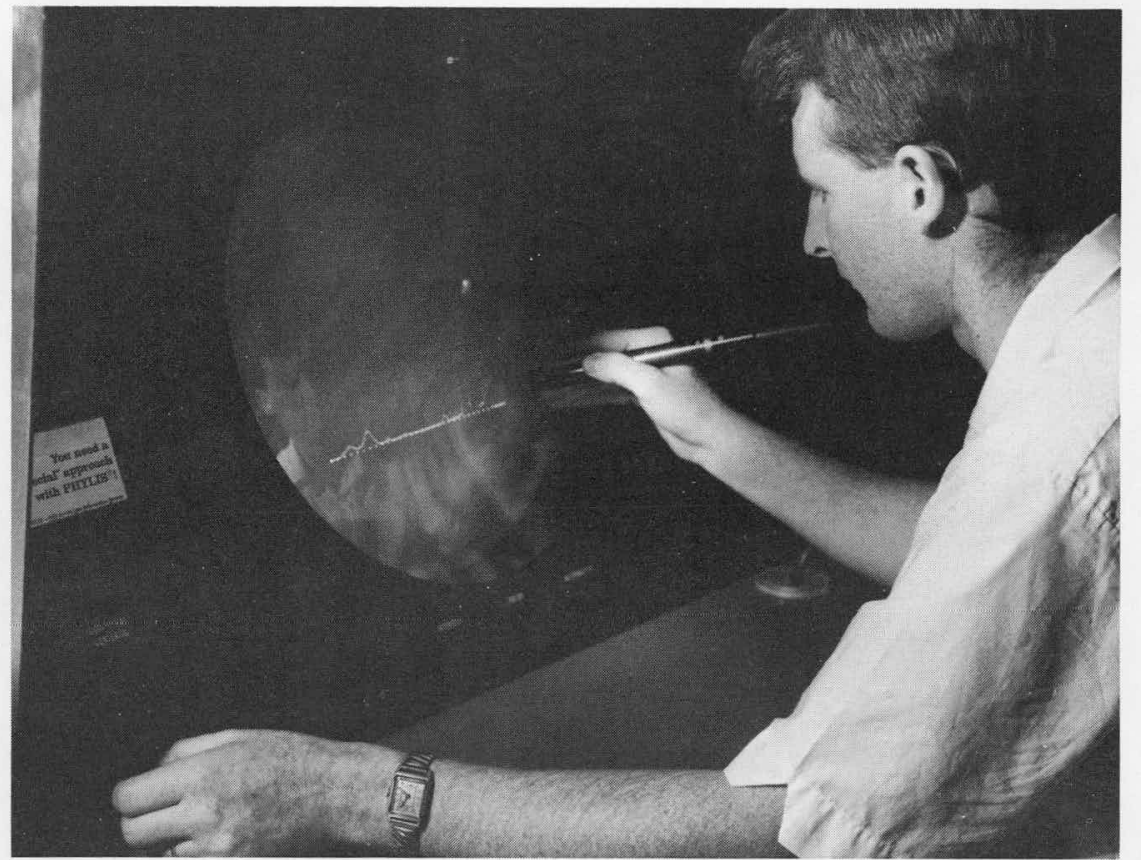

Fig. 6. Close-up view of an operator using the "light-pen" to analyze a pulse-height spectrum displayed on the DD16B oscilloscope. 
The system has been used in a great variety of applications. The Fortran programs used during the progress of experiments include the WOMBAT routine for computing the kinematics of nuclear reactions and the program SPECTO often run in connection with experiments performed with the wide-range magnetic spectrograph at the Tandem. DIDJERIDOO (a large machine-language program) has been used widely in recording and analyzing data, especially in multiparameter experiments (such as angular-correlation experiments, neutron time-of-flight experiments, particle-identification experiments, lifetime measurements, etc.). Users at the 4-MeV Van de Graaff have employed the computer system mainly in conjunction with neutron scattering experiments, which involve quite elaborate computations to guide the course of the experiment. (The link to the 3600 is of great value here.) It has also been used for the direct control of experiments at the Tandem, e.g., in measurements of "blocking effects." (In the latter, a beam incident on a thin single crystal is scattered from the nuclei of atoms in the lattice, and the emergence of the charged particles is blocked in certain sharply defined directions corresponding to the crystal planes.) 
Fourteenth' Annual Conference on Mass Spectrometry and Allied Topics Dallas, Texas, 22-27 May 1966

\section{PHOTOIONIZATION OF VAPORS OF INORGANIC ELEMENTS AND COMPOUNDS}

J. Berkowitz and W. A. Chupka

A vacuum ultraviolet monochromator has been combined (Fig. 7) with a very-high-transmission magnetic mass spectrometer to make possible photoionization studies of vapor species of low concentrations, such as occur in molecular beams formed by effusion from hightemperature Knudsen cells. Photoionization cross sections as a function of photon energy have been measured for a number of molecules of several elements and metal halides. Very accurate ionization potentials and dissociation energies have been determined in favorable cases.

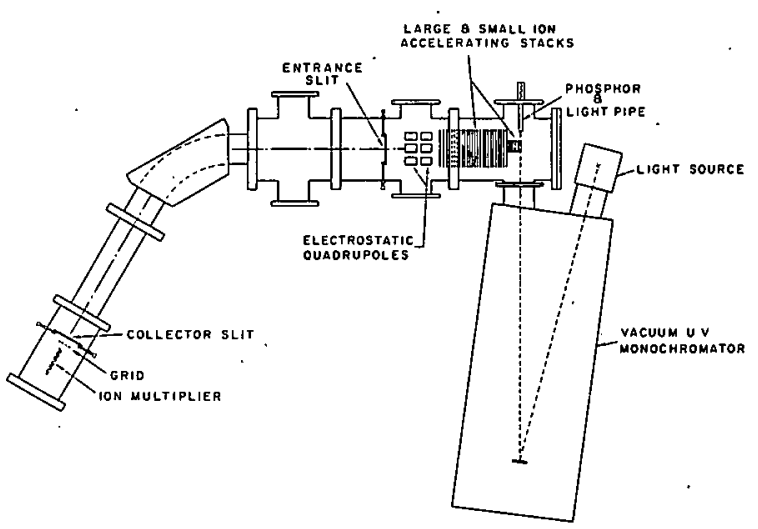

Fig. 7. Schematic diagram of the photoionization machine.

PHOTOIONIZATION OF THE LOWER ALIPHATIC ALCOHOLS

W. A. Chupka and K. M. Refaey*

The photoionization of methanol, ethanol, n-propanol, and iso-propanol has been studied with monochromatic photons from threshold to $14 \mathrm{eV}$ by mass analyzing the ionic products. The data have been

\footnotetext{
*Address after 30 June 1966: U. A. R. Atomic Energy Establishment, Cairo, U. A. R.
} 


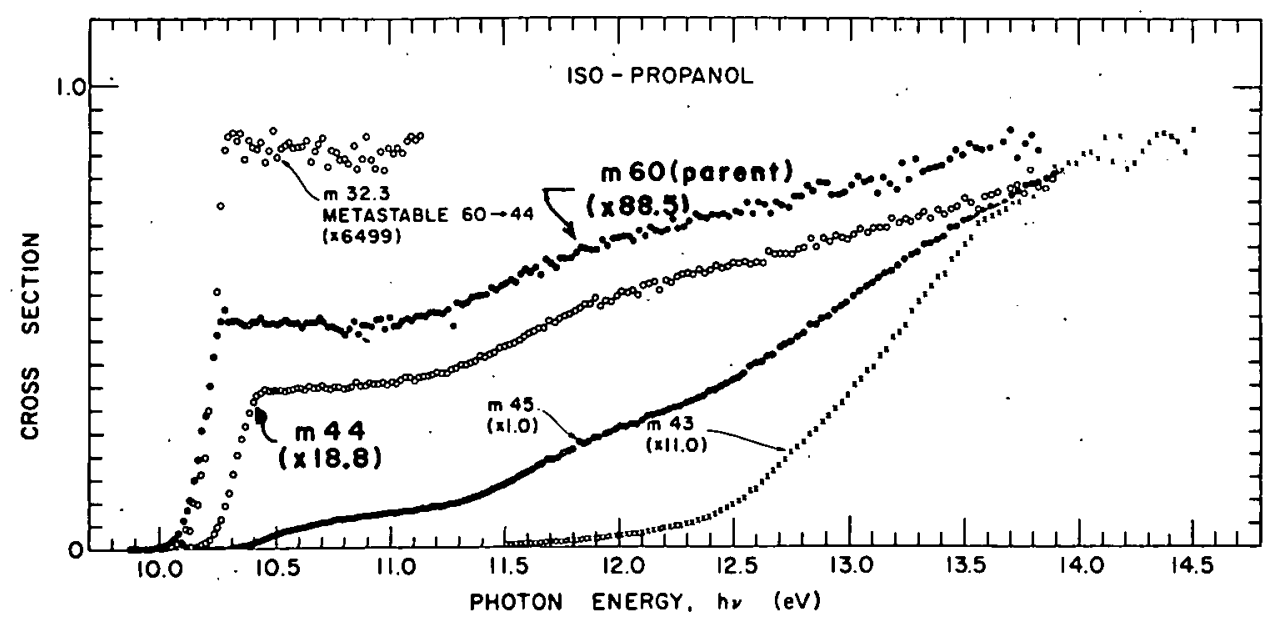

Fig. 8. Photoionization of isopropanol.

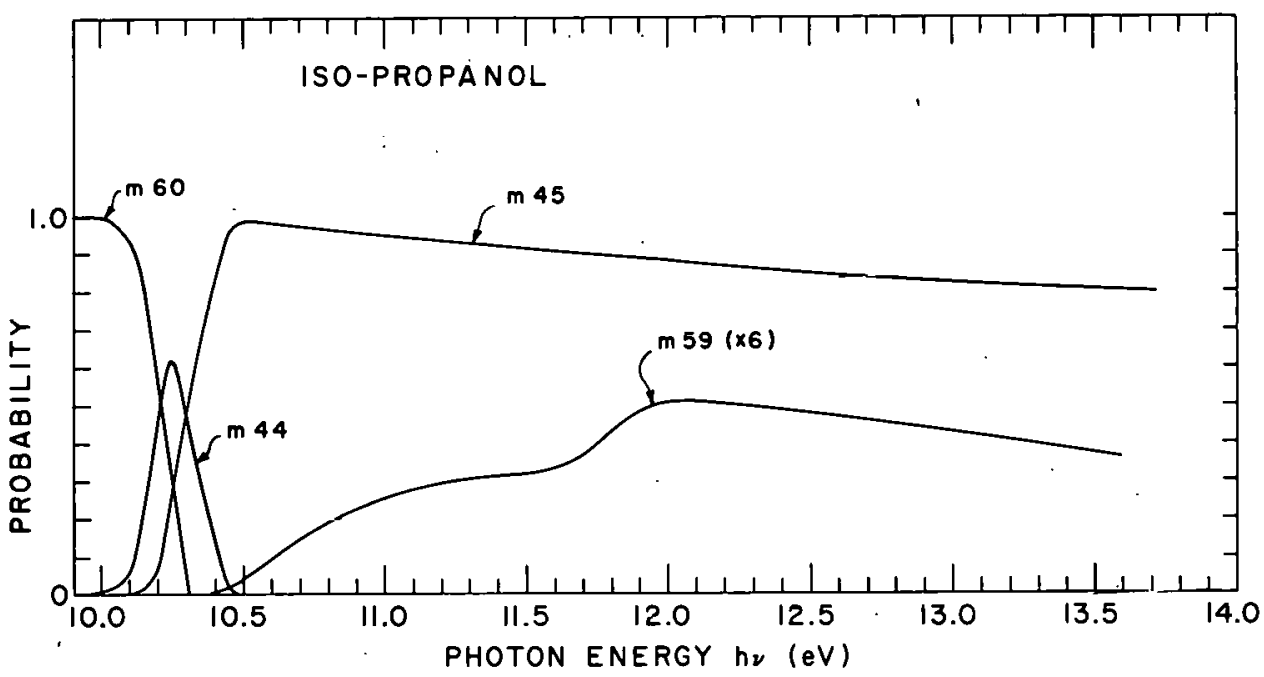

Fig. 9. Breakdown curves for the isopropanol ion. The ordinate is the probability of forming the indicated ion; the abscissa is the sum of the internal energy of the isopropanol ion and its ionization potential. As seen from the curves, the most important fragmentation processes are dissociation of iso- $\mathrm{C}_{3} \mathrm{H}_{7} \mathrm{OH}^{+}$(mass 60) into $\mathrm{C}_{2} \mathrm{H}_{4} \mathrm{O}^{+}$(mass 44 ) $+\mathrm{CH}_{4}$ and into $\mathrm{C}_{2} \mathrm{H}_{4} \mathrm{OH}^{+}$(mass 45 ) $+\mathrm{CH}_{3}$. The dis sociations become energetically possible in this order. But since the first involves rearrangement of the hydrogens whereas the second is a simple bond-breaking process, the latter becomes the dominant process almost as soon as it becomes energetically possible. The dissociation into $\mathrm{C}_{3} \mathrm{H}_{6} \mathrm{OH}^{+}$ (mass 59) $+\mathrm{H}$ is also a simple bond-breaking process, but it is energetically least favored and has a low probability even at higher. energies. 
treated to yield breakdown curves for the parent ions as well as appearance potentials of the major fragments. The breakdown curves obtained in this investigation were in general agreement with those obtained earlier by workers who used the charge-exchange technique. Breakdown curves that had been predicted from the statistical theory of mass spectra were in error because of assuming:incorrect dissociation mechanisms and using an erroneous mathematical approximation. The latter causes the rate constants to vary much more slowly with energy than is observed. This was noticed by several authors, and much better approximations have been developed.

The direct experimental results on the alcohols have been obtained as the ionization-efficiency curves of the parent, metastable, and fragmentions. Those for iso-propanol are.shown in Fig. 8. The breakdown curves, which are the normalized fractional derivative curves computed from the photoionization-efficiency curves [i.e., the plots.of $\left.\left(d_{\sigma_{i}} / d E\right) /\left(\sum_{j} d \sigma_{j} / d E\right)\right]$ are, shown in Fig. 9. These were obtained by use of the computer and are smoothed out so as to present the most probable dissociation pattern. ${ }^{1}$

${ }^{1}$ K. M. A. Refaey, ANL Physics Division Informal Report PHY-1966A, May 1966.

STUDIES OF COLLISION-INDUCED DISSOCIATION AND ENDOTHERMIC ION - MOLECULE REACTIONS

K. M. Refaey* and W. A. Chupka

The cross sections for the dissociation of $\mathrm{C}_{3} \mathrm{H}_{8}{ }^{+}$, $\mathrm{C}_{2} \mathrm{H}_{4}^{+}$, and $\mathrm{O}_{2}^{+}$on collision with $\mathrm{A}, \mathrm{He}$, and $\mathrm{H}_{2}$, have been investigated *Address after 30 June 1966: U. A. R. Atomic Energy Establishment, Cairo, U. A. R. 


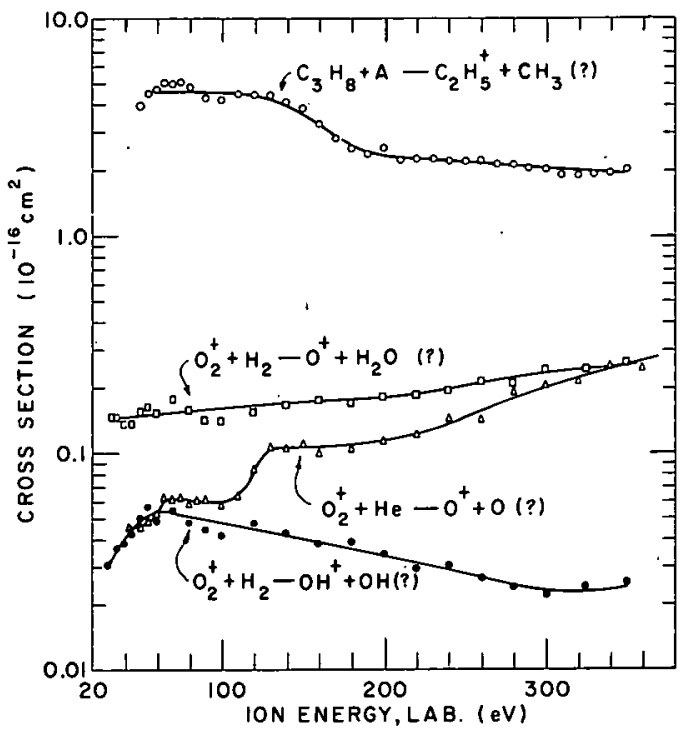

Fig. 10. Energy dependence of the cross sections for the processes indicated.

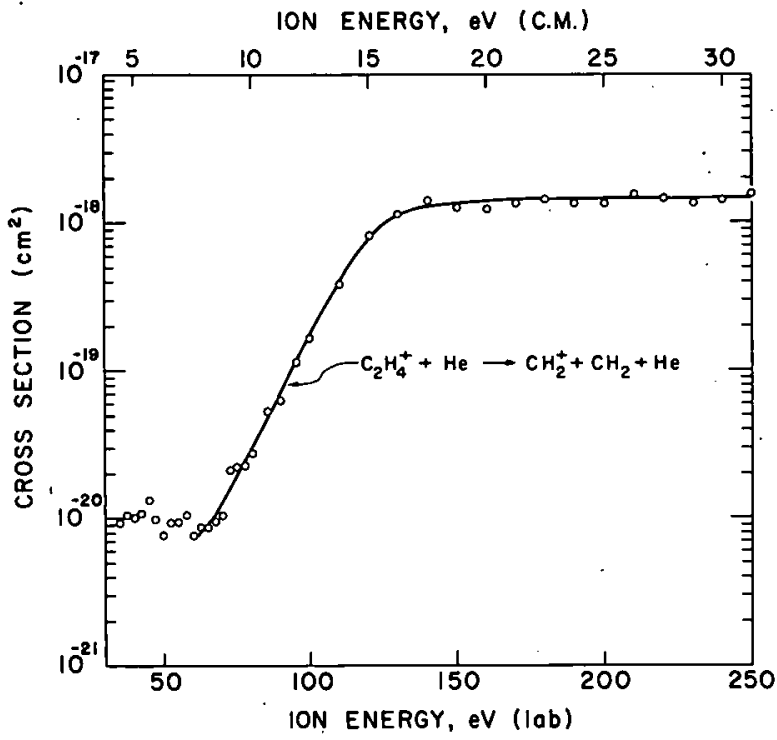

Fig. 11. Energy dependence of the cross section for the process indicated.

over the energy range $15-400 \mathrm{eV}$. In the case of $\mathrm{H}_{2}$, some products of ion-molecule reactions were also investigated. The kinetic energy of the fragments produced in the dissociation of $\mathrm{C}_{3} \mathrm{H}_{8}{ }^{+}$were measured.

An ion source with separate ionization and collision chambers was constructed. Ions produced by electron impact were accelerated through a potential $V_{1}$ and entered the collision chamber with energy $\mathrm{eV}_{1}$. The products of collision were found to appear in the mass spectrum at the mass positions given by the relation $\mathrm{m}^{*}=\mathrm{m}_{\mathrm{f}}{ }^{2} \mathrm{~V}_{1} / \mathrm{m}_{\mathrm{p}} \mathrm{V}$ $+\left(1-V_{1} / V\right) m_{f}$, where $m_{f}$ and $m_{p}$ are the masses of the fragment and parent ions, respectively, and $\mathrm{V}$ is the total accelerating potential.

Figure 10 shows the energy dependence of the cross sections of some of the processes investigated. The low-energy limit was imposed by the collision-product peaks merging into the normal peaks. In the case of the dissociation of $\mathrm{O}_{2}{ }^{+}$by collision with $\mathrm{He}$, the cross section was observed to be large below the dissociation of the electronic ground state $\mathrm{O}_{2}{ }^{+}\left({ }^{2} \pi_{g}\right)$. Approximate appearance-potential measurements at this energy indicate that the dissociation is due to the electronic metastable state $\mathrm{O}_{2}{ }^{+}\left({ }^{4} \pi_{u}\right)$ which lies about $4 \mathrm{eV}$ above the ground state. 
Figure 11 shows the energy dependence of the cross section for the dissociation of $\mathrm{C}_{2} \mathrm{H}_{4}{ }^{+}$on collision with $\mathrm{He}$. The cross section for this process drops appreciably and a threshold at about $62.5 \pm 2.5 \mathrm{eV}$ in the laboratory can be established. This corresponds to an energy of $7.81 \pm 0.31 \mathrm{eV}$ in the center-of-mass system. This value is in agreement with a previously reported one. The cross section below this value is due to impurities in the He gas.

Since the parent ions were produced by electron impact, their internal-energy distribution made it difficult to obtain a sharp value of the thresholds for the processes investigated. To remove this difficulty, a recently constructed ion source employs photon impact to produce the parent ion in a selected vibrational or electronic state. Measurements using this new ion source are in progress. 


\section{ABSTRACTS OF PAPERS ACCEPTED FOR PUBLICATION}

PARITY MIXING IN Hf ${ }^{1} 80$

R. D. Laws on and R. E. Segel

Phys. Rev. Letters (30 May 1966)

The decay of the $1143-\mathrm{keV} 8^{-}$state in $\mathrm{Hf}^{1} 80$ has been considered. An anomaly in the conversion coefficients in the $57-\mathrm{keV}$ decay from this state had been taken by Goldhaber and McKeown as indicating a possible parity mixing in the $8^{-}$state. We show that the amount of mixing required to fit the conversion data requires much more than the experimentally allowed quadrupole component in the $501-\mathrm{keV}$ transition to the $6^{+}$state. It is also shown that because of the requirements of band mixing, the decay of the $8^{-}$state is rather insensitive to parity mixing.

J DEPENDENCE IN THE $\left(\mathrm{He}^{3}, a\right)$ REACTION

L. L. Lee, Jr., C. Mayer-Böricke, and R. H. Siemssen Phys. Rev. (22 July 1966)

The reactions $\mathrm{Fe}^{56}\left(\mathrm{He}^{3}, a\right) \mathrm{Fe}^{55}$ and $\mathrm{Ni}^{60}\left(\mathrm{He}^{3}, a\right) \mathrm{Ni}^{59}$ have been studied with particular attention to the dependence of the angular distribution on the total angular-momentum transfer. Distinct differences in phase were observed in the angular distributions corresponding to $\ell=3$. neutron pickup to states of different spins. Less pronounced differences were observed for $\ell=1$ transitions. All angular distributions showed oscillations about an exponential decrease in cross section with increasing angle. This lack of distinct character in the angular distributions may limit the usefulness of the $\left(\mathrm{He}^{3}\right.$, a) reaction as a spectroscopic tool. 
ANOMALY IN THE ENERGY DEPENDENCE OF THE ANGULAR DISTRIBUTIONS FOR DEUTERONS SCATTERED FROM $\mathrm{Mg}^{2} 4$ IN THE ENERGY RANGE FROM 6 TO 13 MEV

C. Mayer-Böricke and R. H. Siemssen

Z. Naturforsch.

Angular distributions from elastic scattering and from $2^{+}$ inelastic deuteron scattering from $\mathrm{Mg}^{24}$ were measured at various energies.in the range from $E_{d}=6$ to $13 \mathrm{MeV}$. Yield functions were measured in $50-\mathrm{keV}$ steps at $90^{\circ}$ and $150^{\circ}$. In the region from 10 to 13 $\mathrm{MeV}$, the angular distributions from elastic scattering show an anomalous behavior: instead of new maxima and minima coming in from $180^{\circ}$ and shifting toward smaller angles, a broad maximum at about $100^{\circ}$ splits into two maxima. No such anomalous energy dependence is observed for the angular distributions from inelastic scattering. Thus the Blair phase rule is violated in the energy region of the anomaly; but it holds outside this energy region. In spite of fluctuations in the excitation functions, an optical-model analysis of the elastic angular distributions yields parameters which (with the exception of $W$ ) vary smoothly with energy.

ISOSPIN SELECTION RULE IN THE $C^{12}(d, a) B^{1} 0$ REACTION

L. Meyer-Schützmeister, D. von Ehrenstein, and R. G. Allas Phys. Rev. (22 July 1966)

The violation of the isospin selection rule has been studied in the reaction $C^{12}(d, a) B^{10}$ with deuteron energies between 9 and 12.5 $\mathrm{MeV}$. The differential and total cross sections of the isospin-forbidden transition to the first $\mathrm{T}=1$ state in $\mathrm{B}^{10}$ (the $\mathrm{J}^{\pi}=0^{+}$state at $1.74 \mathrm{MeV}$ excitation) has been compared with the cross sections of the isospinallowed transition to the ground state $\left(J^{\pi}=3^{+}, T=0\right)$, the first excited state $\left(J^{\pi}=1^{+}, T=0\right.$ at $\left.0.72 \mathrm{MeV}\right)$ and the third excited state $\left(\mathrm{J}^{\pi}=1^{+}\right.$, $\mathrm{T}=0$ at $2.14 \mathrm{MeV}$ ). Mostly the intensity of the $\mathrm{T}=1$ alpha group is less than $1 \%$ of the yield of the a groups leading to the neighboring $\mathrm{T}=0$ states. This reduction is due not only to isospin forbiddenness but also to angular-momentum and parity selection rules which apply. in this particular $(d, a)$ reaction for which both the initial and the final state have $\mathrm{J}^{\pi}=0^{+}$. The weighting factors have been calculated by use of the Hauser-Feshbach estimates. After these factors have been applied, the $T=1$ alpha group has an intensity of about $10 \%$ relative to the other three $\mathrm{T}=0$ transitions at a deuteron energy of $9 \mathrm{MeV}$ and $1-2 \%$ at an energy of $11 \mathrm{MeV}$. The small yield is ascribed to the isospin selection rules that to a certain 
extent govern this $\mathrm{T}=1$ transition. In the energy range from 9 to $11 \mathrm{MeV}$, the angular distribution of the $T=1$ state stays fairly constant and is nearly symmetric around $90^{\circ}$. The yield decreases steadily. At deuteron energies higher than $11.5 \mathrm{MeV}$, the angular distribution changes drastically and becomes strongly forward peaked and strongly asymmetric around $90^{\circ}$, and the total yield increases slightly. We assume that this behavior indicates a direct-interaction mechanism in which the process of mixing the isospins takes place at the surface of the nucleus. Coulomb excitation during the process of $d$ capture or a emission might be responsible for the isospin violation at higher deuteron energies.

MÖSSBAUER STUDY OF $\mathrm{Kr}^{83}$ IN THE COMPOUND KrF ${ }_{2}$ S. Ruby and H. Selig (Chemistry)

Phys. Rev. (8 July 1966)

The compound $\mathrm{KrF}_{2}$ has been studied by use of the techniques of Mossbauer spectroscopy. The results are that (a) the interaction energy is $\mathrm{e}^{2} \mathrm{qQ} g=130 \pm 4 \mathrm{~mm} / \mathrm{sec}=960 \pm 30 \mathrm{mHz}$, (b) the ratio of the nuclear quadrupole moment of the excited state to that of the ground state is $R=Q_{e} / Q_{g}=1.70 \pm 0.02$, and (c) the isomer shift referred to atomic krypton is $1.50 \pm 0.10 \mathrm{~mm} / \mathrm{sec}$. These results are interpreted as supporting the infrared, Raman, and NMR results which other groups had previously obtained for this compound and as confirming the earlier conclusions reached with the analogous compound $\mathrm{XeF}_{2}$. The quadrupole moment of the first excited state of $\mathrm{Kr}^{83}$ is found to be $0.459 \pm 0.006$ barns, and the fractional decrease in charge radius between the first excited state and the ground state is approximately $4 \times 10^{-4}$.

DISCREPANCIES IN PROTON-TRANSFER REACTIONS TO STATES WITH DIFFERENT ISOBARIC SPIN

R. H. Siemssen, G. C. Morrison, B. Zeidman, and H. Fuchs*

Phys. Rev. Letters (6 June 1966)

Relative spectroscopic factors from the $\left(\mathrm{He}^{3}, \mathrm{~d}\right)$ reaction are compared with those from the $(d, n)$ reaction leading to the low $T=0$ states and first $T=1$ states in the odd-odd nuclei $B^{10}, N^{14}$, and $A 1^{2} 6$.

\footnotetext{
*

"Hahn Meitner Institut, Berlin, Germany.
} 
In each case studied, the relative spectroscopic factor for the $T=1$ state deduced from the $(d, n)$ reaction is less than the spectroscopic factor from the $\left(\mathrm{He}^{3}\right.$, d) reaction, the spectroscopic factors for the $\mathrm{T}=0$ states being normalized to each other for the two reactions. This difference is independent of the incident energy. It is found to be largest for $B^{10}$, for which it is approximately a factor of 3 . 


\section{PUBLICATIONS SINCE THE LAST REPORT}

PAPERS

NUCLEAR RESONANCE FLUORESCENCE IN $\mathrm{Kr}^{82}$

G. B. Beard

Phys. Rev. 145, 862-865 (20 May 1966)

A NOTE ON THE MEASUREMENT OF THE ENERGIES OF GAMMA RAYS FROM DECAY OF Ga66

R. E. Coté, R. Guso (Special Materials \& Services), S. Raboy,

R. A. Carrigan, Jr., *A. Gaigalas,* R. B. Sutton, *and C. C. Trail

Nucl. Phys. 777, 239-240 (March 1966)

PROTON REACTION CROSS SECTIONS AND STRENGTH FUNCTIONS

A. J. Elwyn, A. Marinov, and J. P. Schiffer

Phys. Rev. 145, 957-962 (20 May 1966)

ISOBARIC-ANALOG STATES IN Sc ${ }^{49}$

K. W. Jones,$\ddagger$ J. P. Schiffer, L. L. Lee, Jr., A. Marinov, and

J. L. Lerner (Chemistry)

Phys. Rev. 145, 894-900 (20 May 1966)

THE ANGULAR-MOMENTUM DEPENDENCCE OF THE NUCLEAR LEVEL DENSITY

Donald W. Lang

Nucl. Phys. 77, 545-558 (March 1966)

PARITY MIXING IN Hf 180

R. D. Laws on and R. E. Segel

Phys. Rev. Letters 16, 1006-1008 (30 May 1966)

\footnotetext{
*Carnegie Institute of Technology, Pittsburgh, $\mathrm{Pa}$.

t Brooklyn College, New York.

F Brookhaven National Laboratory.
} 
STUDIES OF ELASTIC SCATTERING OF PROTONS AND DEUTERONS BY CALCIUM ISOTOPES

A. Marinov, L. L. Lee, Jr., and J. P. Schiffer

Phys. Rev. 145, 852-861 (20 May 1966)

GAMMA RAYS FROM B ${ }^{10}+$ p; DECAY SCHEMES AND EXCITATION FUNCTIONS

R. E. Segel, P. P. Singh, S. S. Hanna, and M. A. Grace

Phys. Rev. 145, 736-745 (20 May 1966)

\section{ABSTRACTS AND PAPERS PRESENTED AT MEETINGS}

Proceedings of the Summer Study Group on the Physics of the Emperor Tandem Van de Graaff Region, Brookhaven National Laboratory, 21 June 16 July 1965, Brookhaven National Laboratory Report BNL-948 (C-46)

DISCUSSION: LIGHT SPHERICAL NUCLEI

Dieter Kurath

Vol. I, pp. 223-255, 262-268

SINGLE-NUCLEON TRANSFER REACTIONS

M. H. Macfarlane

Vol. I, pp. 33-60

DISCUSSION: OPTICAL MODEL, DISTORTED-WAVE BORN

APPROXIMATION

J. P. Schiffer

Vol. II, pp. 455-524

HIGH-RESOLUTION MEASUREMENTS OF RESONANCE NEUTRON CAPTURE A. Bloch, * H. E. Jackson, and C. Samour*

Bull. Am. Phys. Soc. 11, 336-337 (April 1966)

* Centre d'Etudes Nucléaires de Saclay, France. 


\section{INFORMAL REPORT}

A. ENERGY DEPENDENCE OF CROSS SECTION FOR COLLISION-INDUCED DISSOCIATION AND ENDOTHERMIC ION-MOLECULE REACTIONS

B. PHOTOIONIZATION OF THE LOWER ALIPHATIC ALCOHOLS AND ETHYLENE

Kamel M. A. Refaey

Argonne National Laboratory Informal Report PHY-1966A. (May 1966) 


\title{
V. PERSONNEL CHANGES IN THE ANL PHYSICS DIVISION
}

\author{
NEW MEMBERS OF THE DIVISION
}

Resident Research Associate

Dr. M. Hla Shwe, Ripon College. Total neutron cross section with fast chopper; precision neutron-capture gamma rays. He is also the ACM-ANL supervisor under the sponsorship of the Office of College and University Cooperation. Came to Argonne on 25 May 1966.

\section{Resident Research Associates (Summer)}

Dr. Akito Arima, University of Tokyo. Theoretical nuclear physics. Came to Argonne on 9 May 1966.

Dr. Mazhar Hasan, Northern Illinois University. Plasma physics. Came to Argonne on 25 May 1966.

Dr. Peter B. Kahn, State University of New York at Stony Brook. Statistical theory of spectra. Came to Argonne on 23 May 1966. 
Dr. Harry J. Lipkin, Weizmann Institute of Science, Rehovoth, Israel. Symmetries and quark models of elementary particles. Returned to Argonne on 26 May 1966 .

Dr. Morley E. Russell, Northern Illinois University. Photoionization studies in a mass spectrometer. Came to Argonne on 26 May 1966.

\section{Technician}

Miss Rosemary Sutter joined the Physics Division on 23 May 1966 to work with R. E. Segel.

\section{PROMOTION}

Mr. George E. Thomas was promoted to Scientific Associate on 1 May 1966.

\section{DEPARTURE}

Mr. John G. McShane, Scientific Assistant, has been.in the Physics Division since 10 May 1960. He terminated at ANL on 4 May 1966. 